\title{
2. Cook Islands: The Cook Islands News and the genesis of FOI
}

\section{COMMIDNIARY}

The Cook Islands News is challenging the Prime Minister and his Cabinet for maintaining secrecy and nondisclosure around all of Cabinet's business in spite of the country's Official Information Act. And the newspaper is fighting several defamation actions which in legal fees are chewing up the equivalent of a whole annual salary for a senior journalist. This is a waste of limited resources, but the cost of being a 'free press'.

\section{JOHN WOODS}

Editor, Cook Islands News, Rarotonga

$\mathrm{F}$

TOR THE Cook Islands, which I represent as the publisher and editor of the national daily newspaper, this is a special opportunity to talk proudly of our independence, of our relative freedom to enjoy and practise the right of free speech and freedom of expression, and of our leading position as the only Pacific Islands nation with Freedom of Information (FOI) legislation. The Cook Islands Official Information Act was cloned from New Zealand's Act, and was implemented in February 2009.

To put this in perspective, we really are tiny with a resident population of some 15,000 people across our 15 beautiful islands. We are an independent state self-governed in free association with New Zealand. The main media institutions were government-owned until 20 years ago, and today my newspaper co-exists alongside Pitt Media Group's Cook Islands Television and Cook Islands National Radio, and two weekly newspapers. There are also seven other private radio stations.

Cook Islands News is fiercely independent. We like to think of our journalism as robust and aggressive. This is thanks to a team of 20 staff including six journalists. We publish six days a week, as a morning newspaper with a paid circulation of about 2500 copies. We achieve saturation coverage with as many as four to ten readers a copy. We use modern technologies, including Computer-to-plate process but we don't have a bindery as we employ up to a 
dozen people each night to hand fold and collate every sheet of the 16 to 20 pages of our newspaper.

For World Press Freedom Day in the Cooks, we devoted three pages to the topic of press freedom. This included our leading article which proclaimed that while we enjoy greater freedom than many of our Pacific neighbours, it is still a fragile freedom.

\section{False allegations of 'trespass'}

In April 2010, our senior reporter Helen Greig was harassed and victimised for daring to publish the truth about a government agency CEO which took a backhander from a Chinese construction company in the form of a motor vehicle. His false allegations of 'trespassing' against Helen led to her arrest, interrogation for three hours and the laying of vaccuous charges.

We have fought this to the point of proving there is no case to answer, the charges have been dropped, and we have received police apology and retraction of false comments (on Radio New Zealand International) by the Deputy Commissioner that Helen had been unlawfully found inside the complainant's home.

We are challenging our Prime Minister and his cabinet for maintaining secrecy and nondisclosure around all of cabinet's business in spite of our Official Information Act. And we are fighting several defamation actions which in legal fees are chewing up the equivalent of a whole annual salary for a senior journalist. This is a sheer waste of our limited resources, but it is the cost of being a 'free press'.

Our OIA itself is handicapped by lack of follow through. Our politicians gloated about being the first in the Pacific to adopt FoI legislation but since then no resources have been applied to education, and our Ombudsman struggles with her role in overseeing the Act. In a way the Act was stillborn, but it will survive.

UNESCO has confirmed to me that our application for funding to promote our OIA has been approved. This will enable us to provide the Ombudsman with some resources (like bilingual brochures, seminars for training government officials, and NIE or newspapers-in-education modules for secondary students) and funding to inform and empower the little people to use the act in our pursuit of the public's right to know.

In our tiny, disparate country, this means we can go ahead with plans to recruit and train six outer islands correspondents. The idea is that we will

16 PACIFIC JOURNALISM REVIEW 16 (2) 2010 


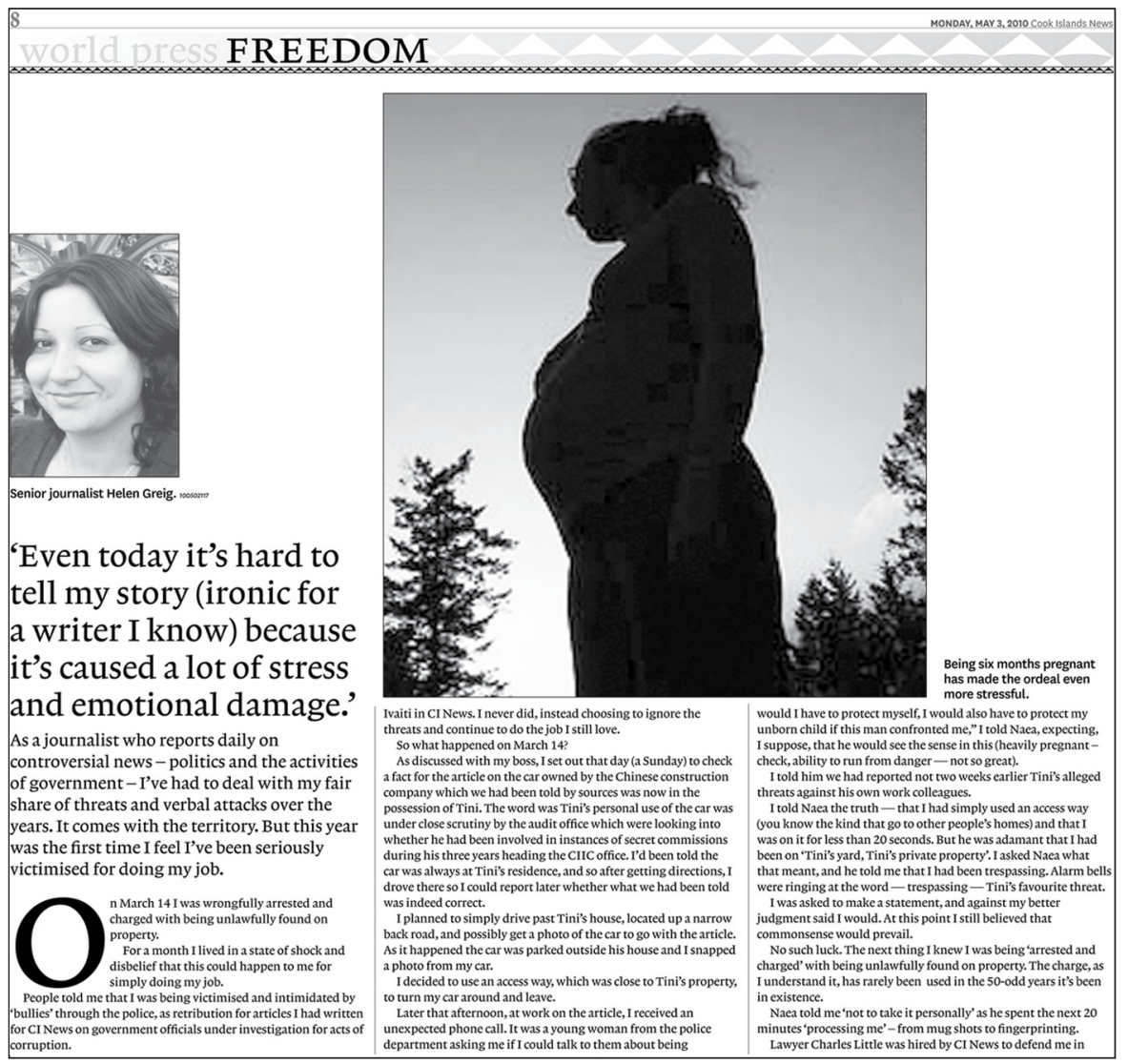

\section{Excerpt from the Cook Islands News media freedom section on 3 May 2010.}

equip them with laptops and cameras, and provide them with space in our newspaper, and with web pages where their news can be opened up to a wider audience. We want expatriate Cook Islanders to be able to comment by way of a bulletin board on what is happening in their home islands. It is about empowering citizens to take control of their destiny.

This brings me to the bigger question of shared regional media issueand of the big challenges now facing independent press development in the Pacific. If freedom of expression is indeed the cornerstone of democracy, as we have heard many times then it is crucial that we continue to collaborate regionally in our quest for unity and agreement on the fundamentals of our people's right to know. 


\section{It's still a fragile freedom Cook Islands News editorial:}

FREEDOM of expression is a civil liberty we mostly take for granted in this country.

We see and hear that freedom working itself out in everyday life-letters to the editor, talk-back radio, the ongoing Sunday flight protests in Aitutaki-and we consider it normal.

But by comparison with our Pacific neighbours, some of whom struggle against censorship and oppression, we are privileged people.

We should all celebrate this today, as we mark World Press Freedom Day.

Certainly Cook Islands News does.

Of course freedom of expression is a constitutional right of citizenship in the Cook Islands, and we rightly pride ourselves on it-as part of being an enlightened democratic state.

But today as we focus on press or media freedom, we also take stock of a few of the challenges and threats to that 'freedom'.

Indeed, when we look at Helen Greig's account of wrongful arrest and police intimidation as a result of doing her job, there also is a disturbing side to reporting of the truth in this peaceful nation.

Helen was arrested, interrogated (for three hours) and charged with trespassing after she took pictures to prove that a vehicle paid for by a Chinese construction company had fallen into the hands of a government agency employee.

The charges against her have since been dropped for the want of a prosecution case, and we have been promised a public apology by police (though the apology and retraction still have not arrived).

Something sinister went on behind the scenes, as men of influence commanded her harassment, following through on their prior threats to 'get her'. That in itself is disquieting.

Our open reporting of opinions on contentious issues draws scorn on an almost daily basis, and legal threats on a weekly basis. It's routine stuff. Mostly we shun them on the basis of the public's right to know. We are fighting several defamation cases in the courts, as part of what it takes to do our job.

On the positive side, we take heart from the fact that we have the only freedom of information law in a Pacific islands country. Our politicians revelled in it when they passed the law, even though it is still handicapped by lack of resources for education, and is still not really effective.

Despite our Official Information Act, the Cook Islands is being denied its right to know at the highest level. The most powerful entity of government, cabinet, is still a stronghold of secrecy and nondisclosure.

We believe, and argue, that the public has every right to know what cabinet decides, what deals it does and what funds it spends.

For the past five years we have pleaded for weekly cabinet media 
briefings, and for release of cabinet minutes and documents, but we are continually denied information. Nowadays we rely on leaks (when it suits an individual) and on papers falling off the back of a truck.

We gladly use this information, but it gets us offside with the power-brokers and is not good for healthy relationships. We have produced examples of weekly public statements from the cabinets of New Zealand and Samoa, recommending that our cabinet follows suit.

Our Prime Minister and Cabinet Services use the lame excuse of a rule that four days must pass to allow cabinet decisions to be notified to affected parties Hopefully they will realise the error of this way, especially if they take seriously last week's potent comment by Jacqui Evans, a former journalist whose Masters thesis deals with the 'Sheraton' hotel debacle.

Evans believes the $\$ 81$ million Sheraton scandal was much worse than the current Toagate financial blunder, and concluded: 'Personally, I think that if we fostered a culture of transparency so that free and immediate online access to cabinet minutes was normal practice, the opportunity would be given for public input and healthy debate so that we don't find ourselves in this fix again.'

It is true that both the Sheraton and Toagate deals were done in the secrecy of Cabinet meetings, with deliberate intent to deny the public of the right to know-and this is wrong morally and democratically.

Yes we may enjoy freedom of expression and we may have a largely free press, but it is a fragile freedom that needs protection and promotion.

\section{John Woods}

\section{Managing Editor}

Cook Islands News

3 May 2010

But what we're looking at in this 21 st century is a new paradigm - a new situation where virtual networks are the conduit for our own expressions of opinion. We now have the Pacific Freedom Forum providing commentary and leadership on the subjects that dominate our thoughts and actions as news practitioners.

\section{PINA conspicuous by its absence}

We see a new alliance emerging despite the structures of old that used to bind and represent our far-flung members. Now I put on my hat as Vice-President of the Pacific Islands News Association (PINA). I feel obliged to address the controversies surrounding PINA since we are gathered here in the name of 


\section{One sided, UNESCO}

\section{Fiji Sun editorial:}

TODAY is World Press Freedom Day. In Brisbane at UNESCO's main global event marking the day there will be lots of huff, puff and one-sided noise about Fiji.

It will be one sided because the Australian organisers have loaded the programme with people who are anti.

They have featured critics of our government, but not any of the many people who have a very different point of view.

What a difference this is to the Pacific Islands News Association (PINA) conference in Port Vila last year. A panel discussion during PINA featured various viewpoints, including from our own Ministry of Information on behalf of the government.

While The Fiji Times representatives staged a walkout when the Ministry of Information representative spoke, the rest of the participants in PINA stayed put and listened.

They understood that the Australian way is not the only way.

UNESCO (United Nations Educational, Scientific and Cultural Organisation) supposedly promotes pluralism of viewpoints. It's a pity UNESCO then did not insist their Australian organisers showed similar balance to what PINA's organisers did.

The failure to do this undermines the credibility of the events in Brisbane.

\section{Leone Cabenatabua}

\section{Editor}

Fiji Sun

3 May 2010

\section{World Press Freedom Day.}

PINA is sadly conspicuous by its absence at this year's gathering, whereas at past UNESCO events like this PINA has always had a strong presence and representation. It behoves me as Vice-President to speak up and to explain why this proud tradition has been broken and why PINA did not take part in this forum. Essentially it boils down to problems within our organisation, and much of this is related to the situation in Fiji where PINA is based and where our administration and news service (PACNEWS) exist under media restrictions and now a radical new media decree.

I read that the Fiji Sun newspaper came out with an editorial (One-sided UNESCO, 3 May 2010) slagging the Brisbane forum for what it prophesied 
would be negative discussion of Fiji's political condition, accusing us of 'Fiji bashing'. This is rich and raggedy stuff. Let me say to the Fiji Sun, which has become the parish pump of the pin-striped puppets who espouse Commodore Bainimarama's cause-pandering as a commercial opportunist to the regime with the effect that it is harvesting government advertising-that nothing could be further from the truth. I've not heard anyone here bagging Fiji, or running anyone from there down except the censors and their bosses. Not till now that is. That is the task that has befallen me: to denounce the regime for its interference in press freedom.

As veteran Pacific reporter Sean Dorney commented recently, PINA once had a well deserved and solid reputation for defending media freedom in the island countries. But that has been lost. And as Lisa Williams-Lahari says, Pacific news media needs a new clean bill of health.

What's wrong with PINA, in my view, is that PINA has lost its mojo. It is a toothless shell of its former self, and the proud history of past members and boards has been relegated to the memory of what once was, but is no longer.

\section{Constitution compromised}

PINA's constitutional purpose in defending freedom of expression has been compromised to the point where most members have lost confidence in its ability to provide leadership and direction.

So, this is the situation with PINA, based on my experience and observations as a board member since July last year when I was elected at the Pacific Media Summit in Vanuatu on a ticket of reform:

1. Our Secretariat is dysfunctional and out of control. The general manager is operating without an employment contract, as he and our president failed to notify the board when we met in December that the GM's contract had expired in November 2009. The office follows no procedures, there is no protocol for administration and reporting, and indeed I cannot even obtain working financial information to show our financial situation. This is alarming and disconcerting, and is a viewpoint held by our most important funding partners.

2. Our Board met in December and passed resolutions (among others) to suspend the membership of Fiji's Ministry of Information (or MINFO which is responsible for censoring Fiji media), but this 
was not communicated or implemented. In fact, MINFO is one of just a dozen current financial members of PINA, having paid their subscription in recent weeks. Our Secretariat cowers under the military regime.

3. We on the Board were never advised that our PACNEWS journalist was detained and questioned over a story he wrote and distributed that did not please the regime. We, the Board, were never advised of facts surrounding the mid-January break-in to our offices and the theft of computers and broadcasting equipment meant for Technical Vocational Education and Training (TVET) projects in the Solomon Islands, Tonga and Samoa. We have now been informed that MINFO is suspected as being responsible for the break in.

4. More recently there have been attacks on our website, compromising its privacy and ability to disseminate information and stories that are critical or negative of the regime and its media imposition.

5. Training has always been a primary activity of PINA, but there is now no concerted programme of events, and funding providers are unhappy. Not to mention our rank and file members who pine for a concerted programme of training that up-skills our employees not just in editorial areas but across the board in management, advertising, technology and new media.

6. Moreover, PINA has a strategic plan that is growing old from inaction. There is no Business Plan, no work plan and no plan to change membership criteria that would make the outfit more inclusive and more democratic.

Apart from anything else, PINA's presence in Fiji and its feeble attempts to continue there are driven by the private agendas of our president and our general manager, whose backers cannot accept that Fiji's media restrictions are the very antithesis of press freedom and what we are supposed to represent.

Fiji's Media Decree, as it stands, is abhorrent and barbaric, and has forced our colleagues here to suffer in silence (and submission) for fear of retribution. The justification given by Fiji's Attorney-General is based around the crazy notion of 'nation building' which is nothing more than claptrap akin to jingoism and all the other ingredients of what it takes to maintain military rule and dictatorship. 
PINA, in this environment, and having lost its edge as an efficient and businesslike organisation, is ineffectual and innocuous. Members have fallen away, and many are reserving their decisions whether to re-subscribe and support the organisation. We now have no members in places like Samoa, French Polynesia, and New Caledonia, and there is a new collective of companies and organisations which have lost patience and will soon form a new structure with which to go into the future.

For my part, I am making a stand here today to issue an ultimatum to our Board: face this pressure, consult past and present members, and bite the bullet to relocate and restructure.

If this cannot be done forthwith, I will add my small weight to the new vanguard that demands change. I shall do the right thing after today, by tendering my resignation unless the Board is prepared to act immediately and urgently. Apart from anything else, I am not prepared to bumble along without financial accountability and transparency due to a complete lack of financial information.

PINA today is at a crossroads, and it is up to my colleagues on the Board to face this reality, and change its direction.

\section{Conclusion}

I once worked for a newspaper with the lofty motto 'Truth without fear', and I wished we in the Pacific could all live by that creed in our work as journalists. Sadly, the rule of the gun, and at times the antiquated customs of autocracies and monarchies, prevent that. At Cook Islands News, in our own small but passionate way, we have adopted the adage that goes like this:

For the cause that needs assistance

For the wrong that needs resistance

And the good that we can do.

John Woods is managing editor of the Cook Islands News. This address was given as one of a series of University of Queensland World Press Freedom Lectures marking the UNESCO WPFD 2010 conference in Brisbane, 4 May 2010. He subsequently resigned as vice-president of PINA and has helped form the Pasifika Media Association (PasiMA).

www.cookislandsnews.com 
Copyright of Pacific Journalism Review is the property of Auckland University of Technology and its content may not be copied or emailed to multiple sites or posted to a listserv without the copyright holder's express written permission. However, users may print, download, or email articles for individual use.

http://www.aut.ac.nz/depts/commstud/journ/pjrsubs.shtml 